استخدام طريقة جون هوايت John White في التحليل الهارموني في بريليود رقم (r) مصنف (•) عند كابالفسكي

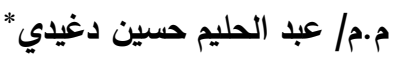

تحت إشراف: أ.د/ محمد عبد الله أحدث**

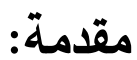

شها القرن العشرين تجديدات متعددة في الموسيقا بكل عناصرها خاصة عناصر اللدن

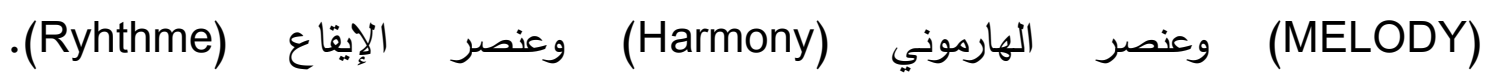
فلقد شها عنصر الهارموني تطورات كثيرة في موسيقى القرن العشرين حتى الغت الفروق بين الغين التآلفات المتوافقة (Consonance) أو المتافرة (Dissonance) كما ألغت أيضاً العلاقات

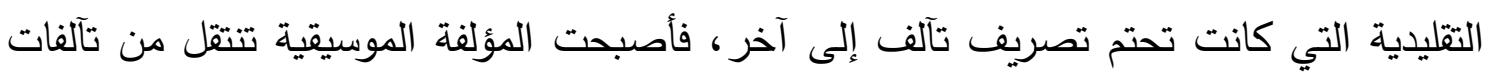

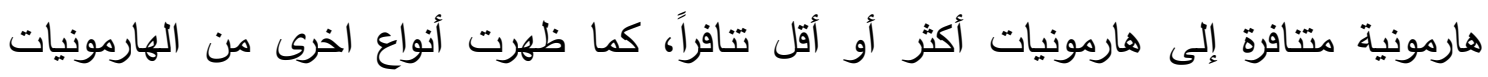

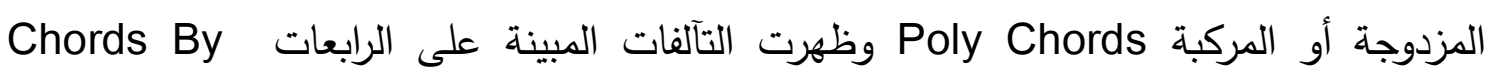

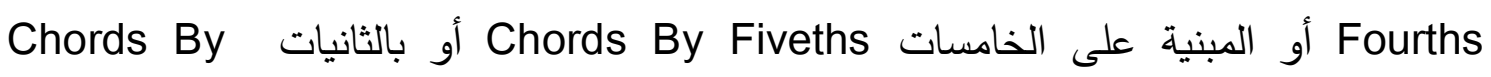

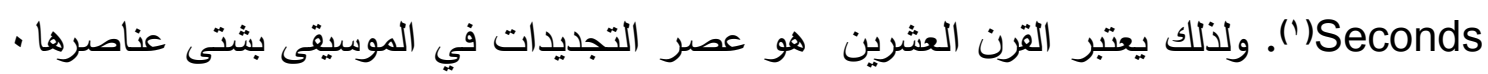
ولقد استخدم معظم مؤلفي القرن العشرين هذه التجديدات في مؤلفاتهم الدختلفة وأصبغوا عليها

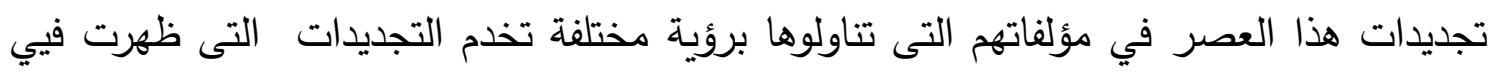

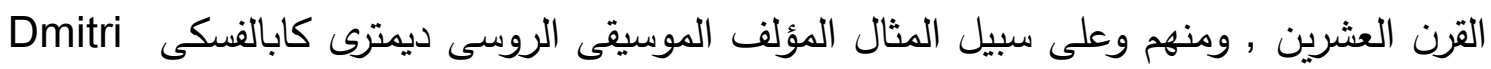
kabalevsky التأليف الموسيقى العالمى , لذا رأى الباحث القاء الضوء على احدى مؤلفاتة للبريليود وهى البريليود

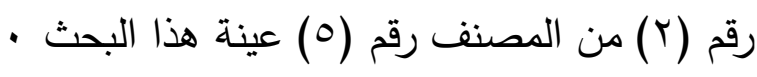

مثكلة البحث

تطور علم وفن الموسيقا على مر العصور الدختلفة إلى جانب تطور استخدام المؤلفين الموسيقيين

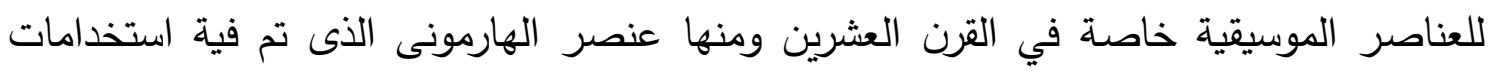
مختلفة واضافات جديدة لبناء التركيبات الهارمونية في القرن العشرين, وكنلك ظهور طرق كثيرة

* عبد الحليم حسين دغيدي: مدرس مساعد بقسم النظريات والتأليف - شعبة تأليف، كلية التربية الموسيقية، جامعة حلوان. ** محمد عبد الله: أستاذ دكتور بقسم النظريات و التأليف - شعبة تأليف، كلية التربية الموسيقية، جامعة حلوان.

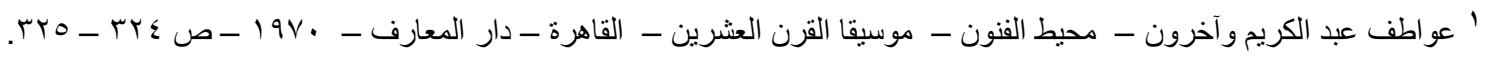

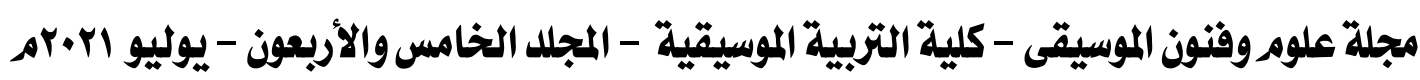


للتحليل ومنها طريقة جون هوايت في التحليل الموسيقى والتى لم يتم التطرق اليها سابقارغم أهميتها في التحليل العالمى لذلك رأى الباحث القاء الضوه على الى استخدام طريقة جون هوايت في التحليل الهارمونى للبريليود رقم (r) مصنف(0) عند كابالفسكى , وذلك حتى يتم الاستفادة منها في التحليل

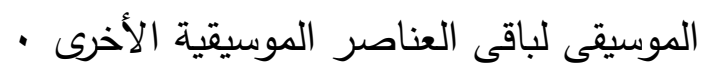

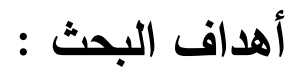

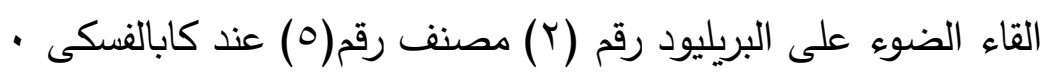

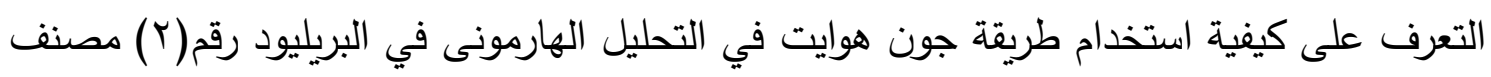

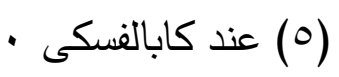
أهمية البحث :

تكمن أهمية البحث في التعرف على البريليود رقم (Y) مصنف رقم (0) عند كابالفسكى وذلك من خلال التعرف على كيفية استخدام طريقة جون هوايت في التحليل الهارمونى لهذه المؤلفة مما يفيد الهي

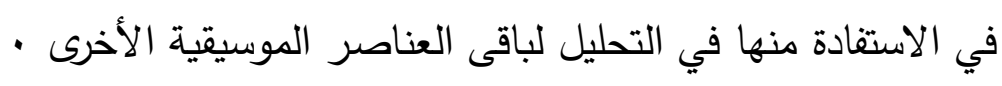
اجراءات البحث : مالبن منهج البحث : وصفي - تحليل محتوى : مراء

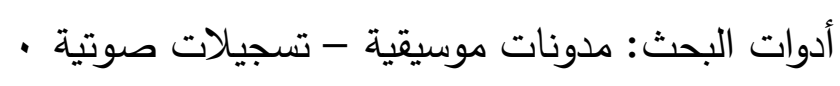

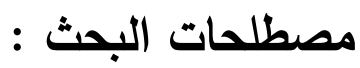

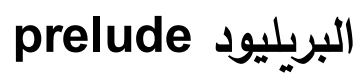

مؤلفة موسيقية تصمم أو تكتب لتؤدى كمقدمة موسيقية لبعض الأعمال مثل الفيوج fugue أو

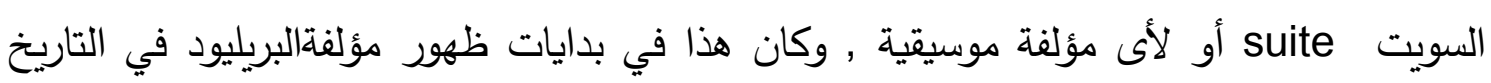

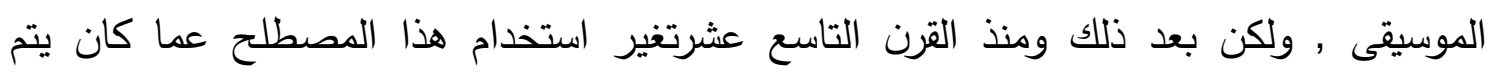

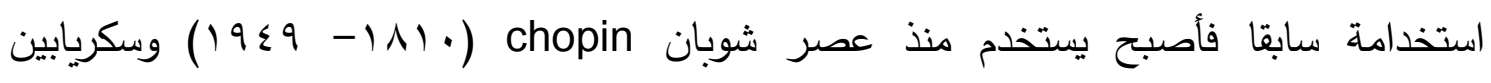

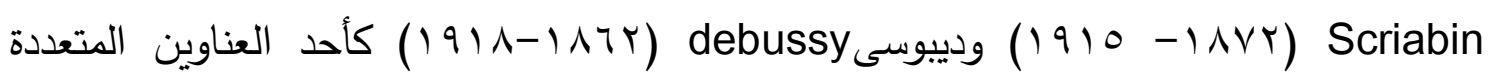
للمؤلفات الموسيقية لآلة البيانو (').

${ }^{1}$ Apel, willi-harvard dictionary of music-second ed-london-heinemann educational-book,s-ltd.1983.p692 مجلة علوم وفنون الموسيقى - كلية التربية الموسيقية - المجلد الخامس والأربعون - يوليو الr.rم 


\section{harmony الهارمونى}

حتى القرن السابع عشر كان يستخدم مصطلح الهارمونى كمعنى عام للصوت الموسيقى ,ثم جاء استخدام التآلفات كنتيجة لاضافة مسافات رأسية لأجزاء اللحنية , وفي المسمى الحديث فإن الهارمونية تعنى بنتء وتكوين ووظيفة وعلاقات بتتابعات وتألفات هارمونية(')

\section{chords by fourths التركيبات الهارمونية بالرابعات}

يتكون التآلف بالرابعات من رابعات فوق بعضها وغالبا ما توضع النغمات بالرابعات كل على حدة وذلك للاحتفاظ بنوعية الصوت المميز للرابعات حتى لا تحدث التركيبات بالرابعات صوتا يشابة التآلفات الثلاثية بالحادية عشرة او بالثالثة عشرة أو بالنغمات المضافة(؟). الارراسات السابقة المرتبطة بالبحث أولا دراسات مرتبطة بمؤلفة البريليود

دراسة عربية بعنوان : البريليود عند شوبان "دراسة تحليلية "(") هدفت هذه الدراسة إلى التعرف على الأساليب المختلفة لصياغة البرليود عند شوبان وكذلك التعرف على عناصر البريليود من الناحية الايقاعية واللحنية والهارمونية وكيفية تناولها, وتعرضت الباحثة إلى الحديث عن حياة شوبان, وتوصلت إلى بعض النتائج خاصسة المتعلقة بالتحليل الهارمونى نذكر منها كثرة استخدام التآلفات الثانوية , استخدام علاقة الوسيط midiant في التحويل بين السلالم المختلفة

\section{التعليق على الدراسة السابقة}

يرى الباحث أن هذه الدراسة تتفق مع البحث الراهن في بعض الأجزاء النظرية للبحث خاصة فيما يتعلق بمؤلفة البريليود وأيضا في استخدام التحليل الهارمونى ولكن تختلف من حيث العصر والثخصية الرئيسية للبحث

1 Sir Westrup, Jack and Harrison, F.Li.Rvised by Wilson, Conrand-Collins pocket dictionary of music-wm. Collins sons and co.Itd. London-1984-p 213-214.

2 persichitte,Vincent-twentieth centur harmony-new York-creative aspects and practice-1978-p.94.

" ايناس سيد محمود عبد الوهاب-البريليود عند شوبان دراسة تحليلية- رسالة ماجستير -غير منشورة-كلية التربية الموسيقية -جامعة

حلوان -القاهرة - م90-1990.

مجلة علوهر وفنوز الموسيقى - كلية التربية الموسيقية - المجلد الخامس والأربعوز - يوليو ابمبم 
(1) دراسة أجنبية بعنوان: التطورات الأساسية في مؤلفة البريليود لآلة البيانو عند سكريابين

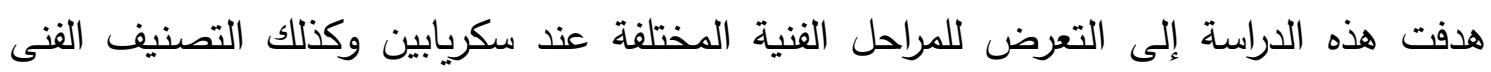
لمؤلفاته الموسيقية وذلك لكل مرحلة على حدة وأيضا إلى استنتاج فلسفة سكريابين من خلال

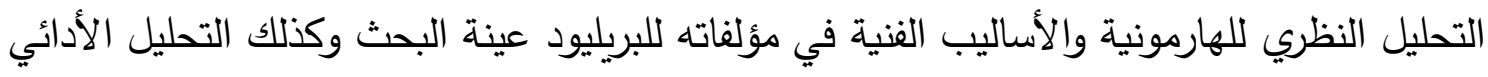
لتلك المؤلفات لآلة البيانو.

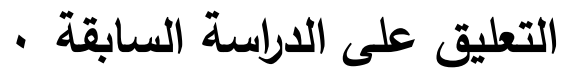

يرى الباحث ان هذه الدراسة السابقة تخدم الاطار النظري للبحث الراهن والخاص بمؤلفة البريليود

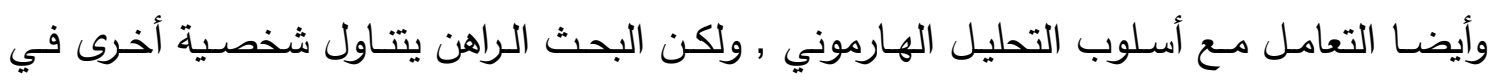
عصر آخر وهى كابالفسكى وهو أحد أهم مؤلفي الموسيقى الروسية في القرن العشرين الترني

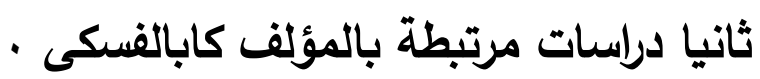

دراسة عربية بعنوان : الدعابة scherzo عند كابالفسكى وأسلوب آدائها على البيانو (؟).

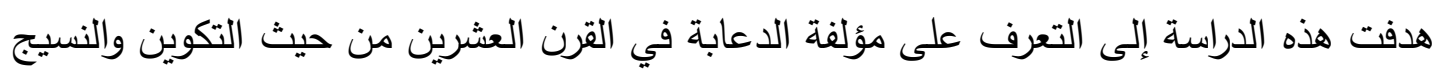

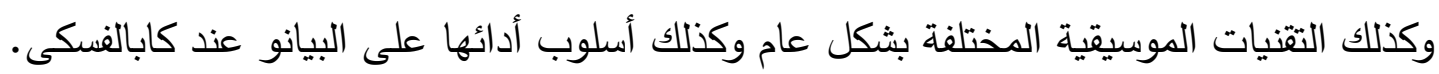
التعليق على الدراسة السابقة.

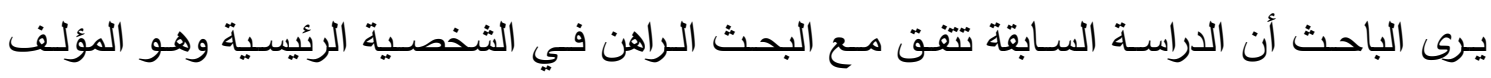

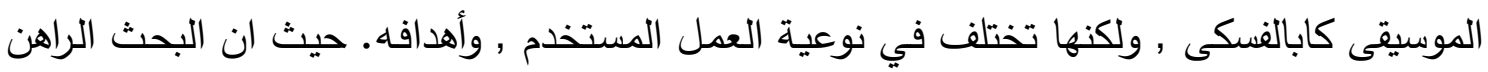
يتناول استخدام طريقة جون هوايت في التحليل الهارمونى للبريليود رقم (r) عينة البحث. دراسة أجنبية بعنوان : تحليل طريقة التعليم الموسيقى عند ديمترى كابالفسكى ومقارنتها بتلك عند كل من سلطان كوداى وكارل أورف(ז) . هدفت هذه الدراسة السابقة إلى التحليل والتعرف على أسلى أسلوب كابالفسكى في طريقة التعليم الموسيقى ومقارنتها بتلك الطرق المختلفة عند كل من كوداى وأورف.

${ }^{1}$ meeks,john-basic development in Scriabin,s preludes for the piano -phd-peabody conservatory of musicUSA-1999.

ب اسماء محمد شومان-الدعابةscherzo عذد كابالفسكى وأسلوب آدائهاعلى البيانو-بحث انتاج منشور -المؤتمر العلمى الأول للبيئة -كلية التربية الموسيقية-جامعة حلوان-القاهرة - 1999.

${ }^{3}$ Tsisserev,Alex-An analysis of the music education methodoiogy of kabalevsky and comparison with Kodaly and orff -university of manioba- Canada- 1993.

مجلة علوم وفنون الموسيقى - كلية التربية الموسيقية - المجلد الخامس والأربعون - يوليو ابr.rم 
التعليق على الدراسة السابقة :

يرى الباحث أن هذه الدراسة السابقة تتفق مع البحث الراهن فيما يختص بالاطار النظرى للمؤلف

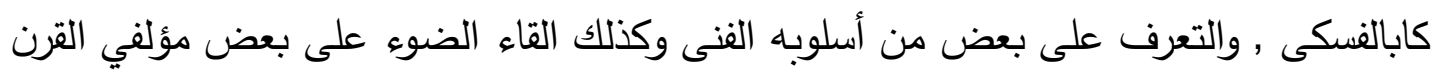
العشرين ,ولكن جاء الاختلاف في أن البحث الراهن يتناول استخدام طريقة جون هوايت في التحليل

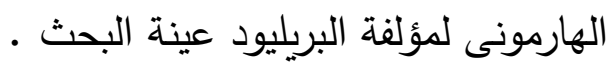
يشتمل هذا البحث على جزئين

أولا الجاتب النظرى ويشتمل على:

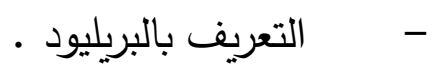

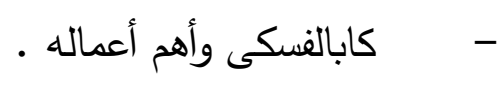

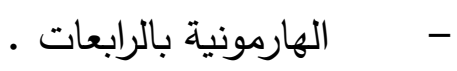
طريقة جون هوايت زمohn white في التحليل . ثانيا الجانب التطبيقى ويشتمل على : الدراسة التحليلية لعينة البحث- نتائج البحث- التوصيات - المراجع - ملخص البحث باللغة العربية - ملخص البحث باللغة الأجنبية .

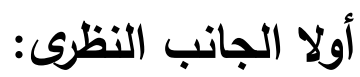
prelude التعريف بالبريليود praludim,vorspiel وبالألمانية prelude , وبالفرنسية praeludium باللاتلتينى

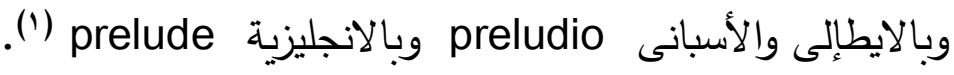
ونبعت فكرة البريليود في العصور المبكرة من خلال آداء الارتجالات القصيرة التى كانت تئدى

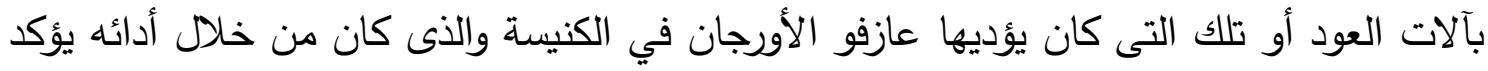

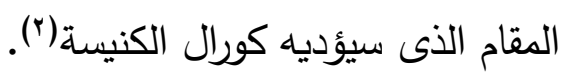

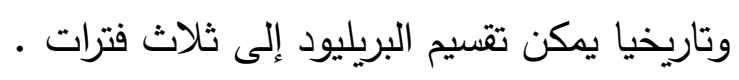

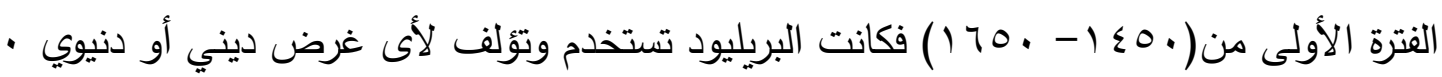

${ }^{1}$ APEL, WILLI -P . 692.

ץ ماكس بنشار - تمهيد للفن الموسيقى - ترجمة محمد رشاد بدران - دار نهضة مصر للطباعة والنشر بالاشتراك مع مؤسستفرانكلين

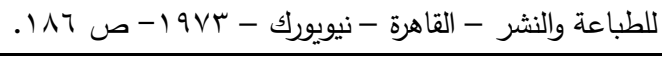
مجلة علوم وفنون الموسيقى - كلية التربية الموسيقية - المجلد الخامس والأربعوذ - يوليو ابr.rمر 


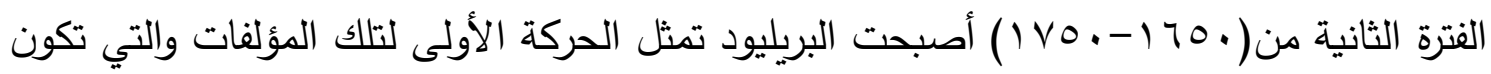

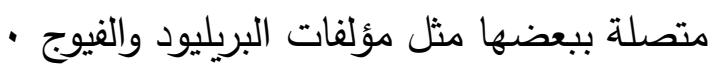
وكانت غالبية مؤلفات البريليود في القرن الخامس عشر وبداية القرن السادس عشر مقطوعات قصيرة في حدود من عشرة إلى عشرون مازورة مع ملاحظة كتابتها لآلات المفاتيح وكتابة أشكال

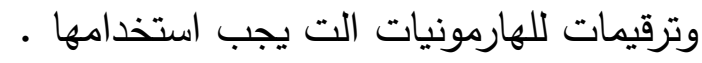
وفي الفترة الثالثة وهى الترن التاسع عشر أصبحت البريليود مؤلفة غير متعلقة أو ترتبط بأى مؤلفة

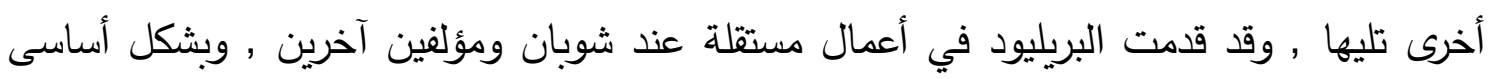

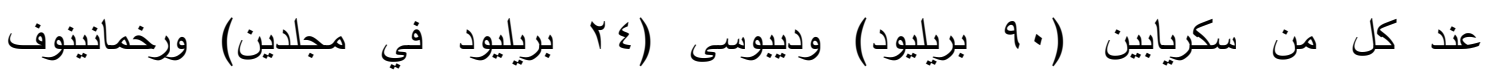
RAKHMANINOV البيانستى المتقدم وكانوا دائما ما يعتمدون في بناء البريليود على استخدام فكرة لحنية صغيرة

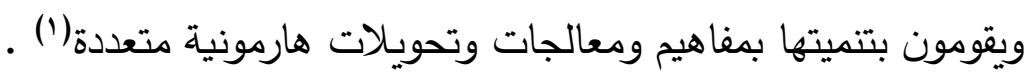

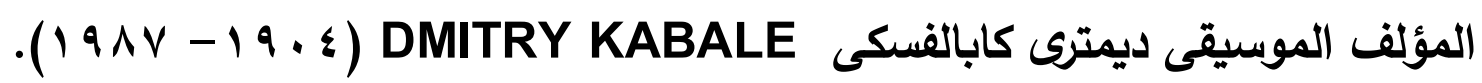
كابالفكى مؤلف روسى تتلمذ على يد كل من مياسكوفسكى MIASKOVSKY (1 (1) - 190 ( )

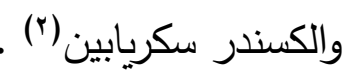
ويصنف كابالفسكى كأحد كبار المؤلفين الروس, وهو ممثل صادق لقطاع كبير من المؤلفين الروس والذين كتبوا موسيقاهم بأسلوب قومى ,ولة دور ا بارزا في الحياة الموسيقية الروسية . ظهرت ميولة الفنية للموسيقا والثعر والتصوير منذ طفولتة ,ووفرت لة اسرتة دراسة مبكرة لتعليم العزف على آلة البيانو • في عام 1911 التحق بمدرسة سكريابين لدراسة البيانو , ثم التحق بكونسير فاتوار موسكو حيث

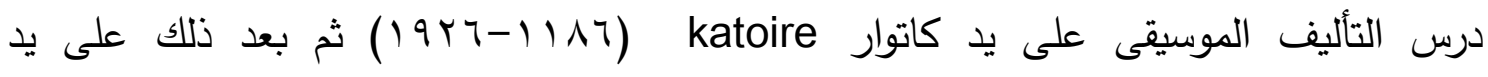
مياسكوفسكى , ومنذ عام • ب ا9 وذلك بعد تخرجة بدأ حياة موسيقية حافلة كمؤلف وقائد أوركسترا

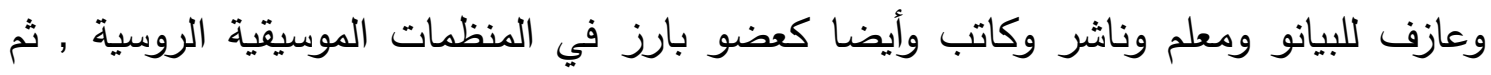

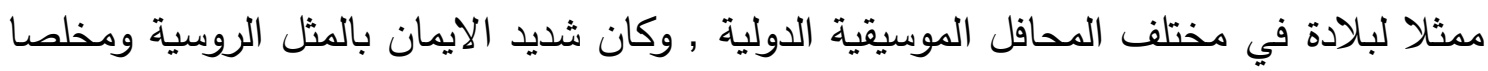

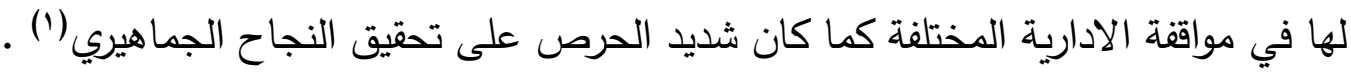

${ }^{1}$ Abel, willi- p. 692-693 .

${ }^{2}$ Sir Westrup,jack and Harrison ,f.l.-p-252.

مجلة علوم وفنون الموسيقى - كلية التربية الموسيقية - المجلد الخامس والأربعون - يوليو ابr.rم 


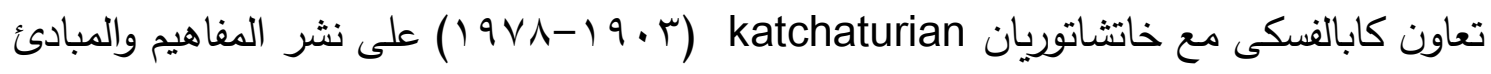
الاشتراكية والآيديولوجيات الجديدة للدولة الروسية وكانت تلك المفاهيم والمعتقدات صعبة الفهم في

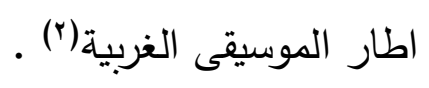

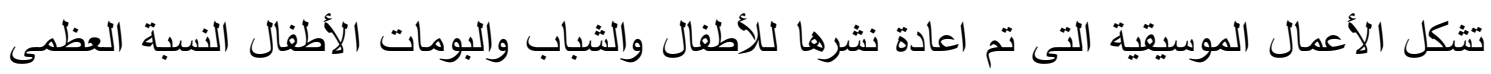
من أعمال كابالفسكى , وكذلك اعادة ترتيب المؤلفات القديمة للآلات الشعبية . ومما يجدر الاشارة الية أن كابالفسكى كان يمتلك طاقة ابداعية كبيرة وقدرة على مساعدة الأطفال

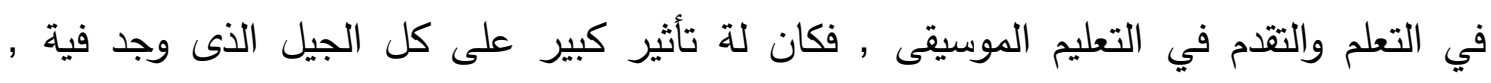

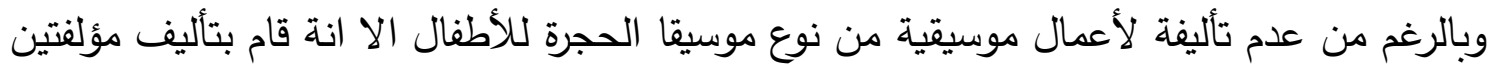

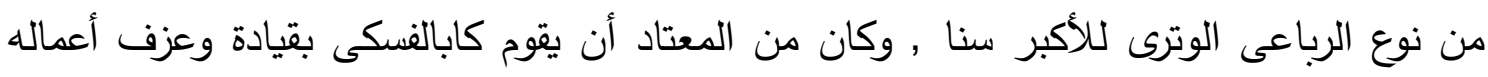

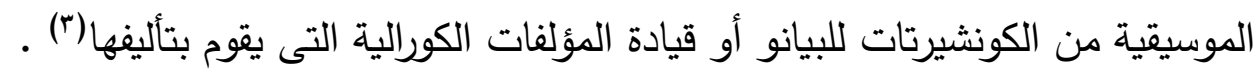

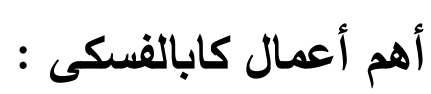

ألف كابالفسكى العديد من الأعمال الموسيقية الهامة وفي مجالات كثيرة نذكر منها :

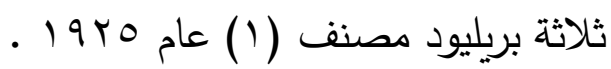

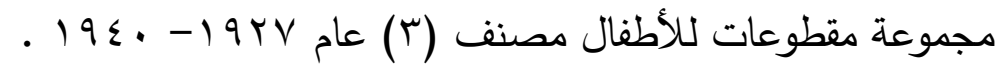

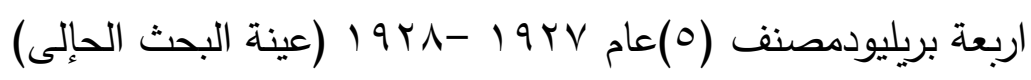

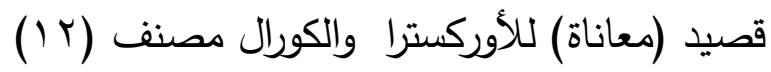

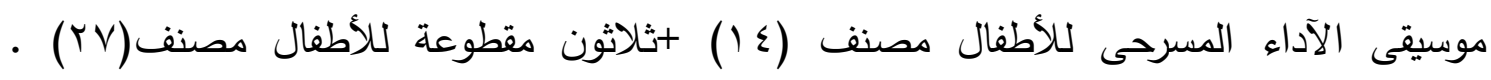

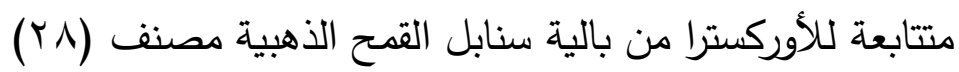

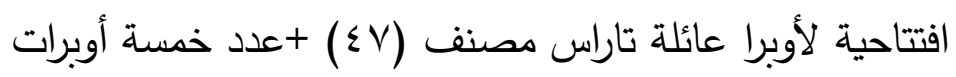

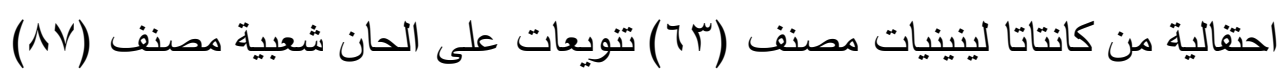
عدد خمسة سيمفونيات ـ وأعمال أخرى كثيرة(؛) .

'سمحة الخولى-القومية في موسيقا القرن العشرين سلسلة كتب يصدرها المجلس الوطنى للثقافتوالفنون والآداب-الكويت-عالم المعرفةيونيو 19V-199

2 Ewen,David-twentieth century music-prentice hall inc.new York-1954-p.199.

${ }^{3}$ kabalevsky,maria-memoriesof my father-nepta-new England piano teacher,s-assoc-inc., 1994-p.3.

4 Sadie,Stanley-the new grove,s dictionary of music and musicians-vol 13 macmillan publishers,-new York2001-p.298-300.

مجلة علوم وفنون الموسيقى - كلية التربية الموسيقية - المجلد الخامس والأربعون - يوليو ابr.rم 


\section{الهارمونية بالرابعات chords by fourths}

استخذم مؤلفي القرن العشرين الهارمونية بالرابعات جنبا إلى جنب مع الهارمونية بالثالثات والتى

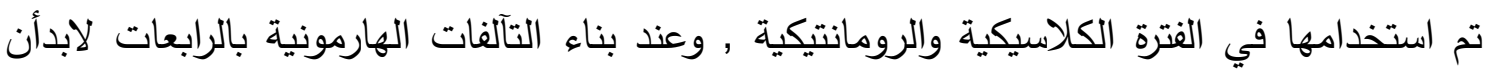
يراعى ان تكتب أولا بشكل يوضح انفصال كل رابعة عن الأخربشكل متتإلى في البداية حتى يتم

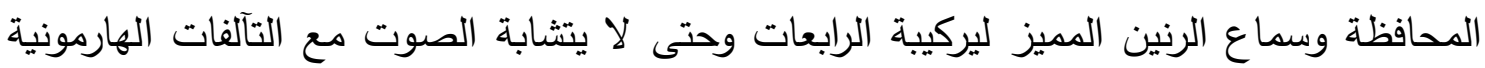

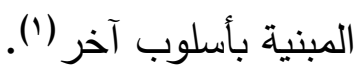

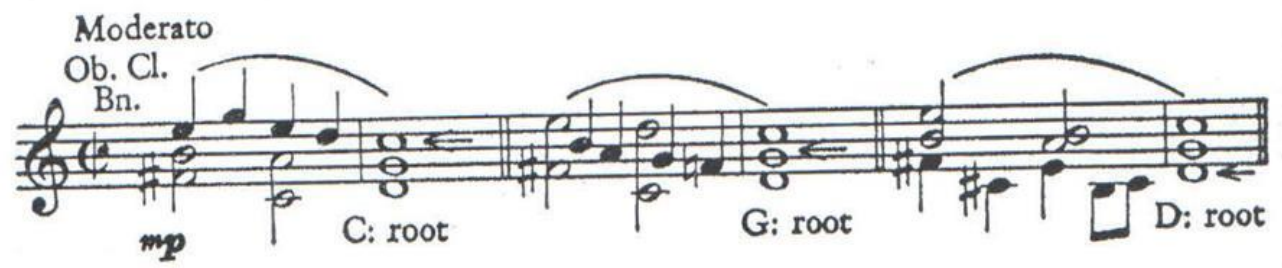

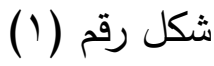

استخذام الهارمونيات بالرابعات

ومن الاستخدامات المتتوعة للتآلفات بالرابعات هو بناء التآلفات الأساسية على مسافة الرابعة التامة

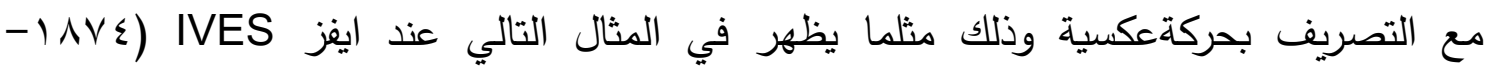
( ( ) $) 9 \leq 0$

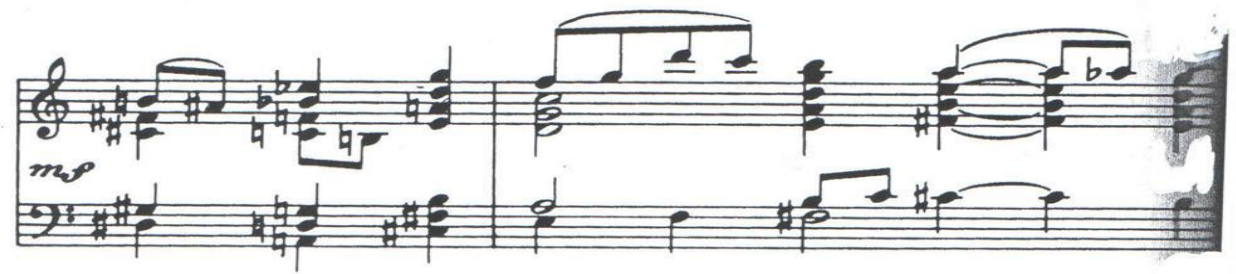

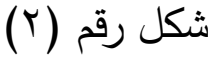

استخدام ايفز لهارمونية بالرابعات مع التصريف بحركة متوازية

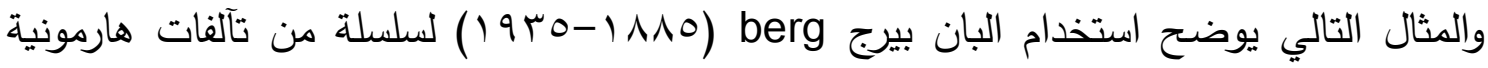
مبنية بالرابعات التامة والمكونة من نغنتين حتى سبع نغمات في مؤلفته فوتسيك وظهرت كل 
حركات التصريف في توازيات , وهى ليست تعتبر كنموذج أو كمثال للتصريفات بالرابعات ولكنها

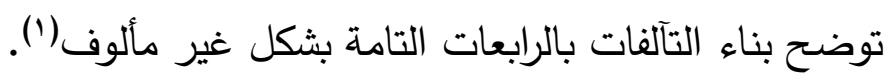

BERG: Wozzeck-Act I Scene 4 (1914-21) p70
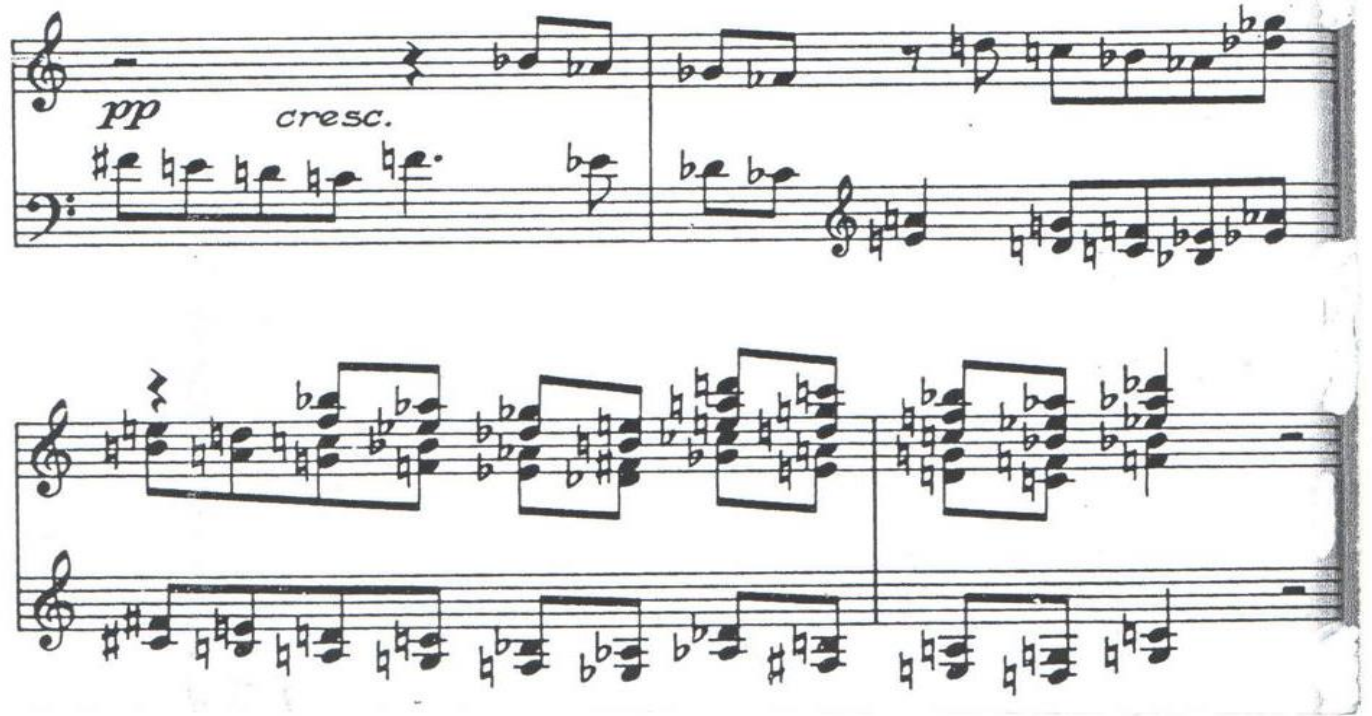

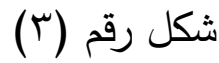

استخدام البان بيرج لهارمونية بالرابعات

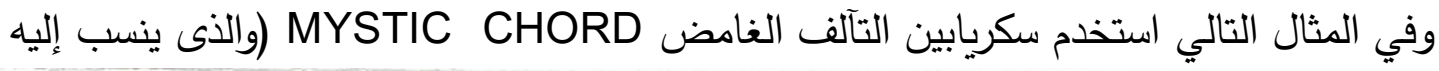
SCRIABIN: Poème, Op. 69 No. 1 (1913)

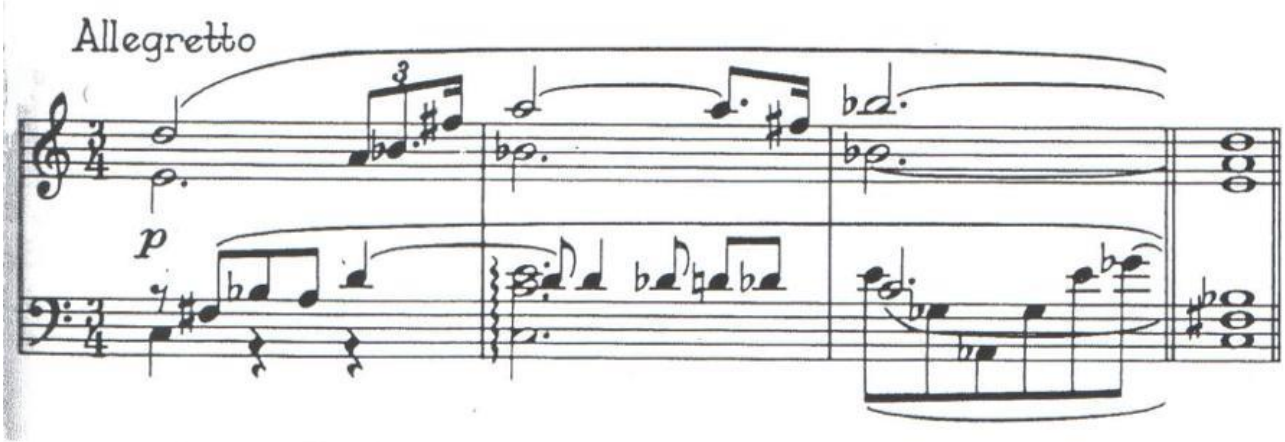

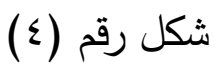

استخدام سكريابين للهارمونية بالرابعات المختلطة

${ }^{1}$ Dallin,leon-p.97-98 .

مجلة علوم وفنون الموسيقى - كلية التربية الموسيقية - المجلد الخامس والأربعون - يوليو ابrمه 
ابتكارة من خلال السلسلة الهارمونية التوافقية ) في تكوين وبناء بالرابعات المختلطة حيث ظهرت

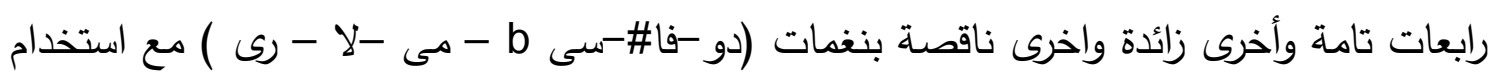
تلك النغمات في تتويعات مختلفة في البناء.

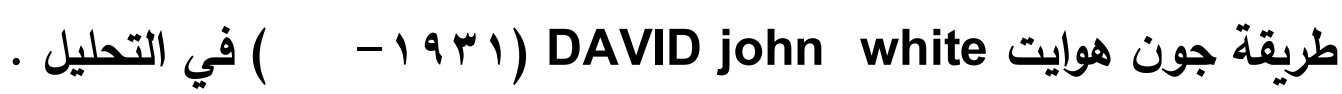
أدى اختلاف وتتوع الأساليب المستخدمة في موسيقا القرن العشرين إلى استخدام أساليب مختلفة

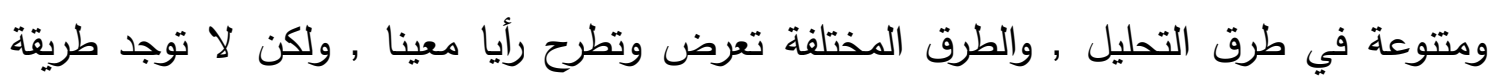

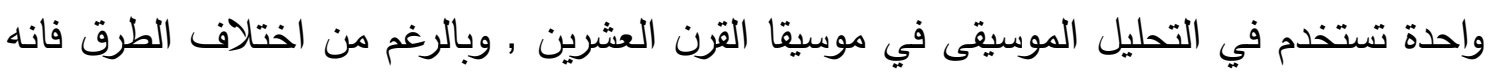

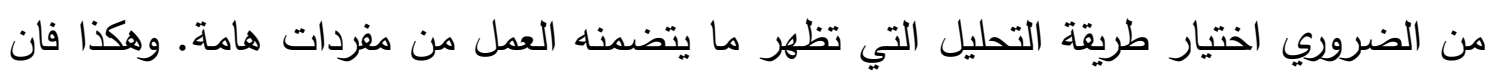
اختيار طريقة التحليل تصبح هى الأساس والبداية عندما نبدأ في تحليل موسيقا القرن العشرين.

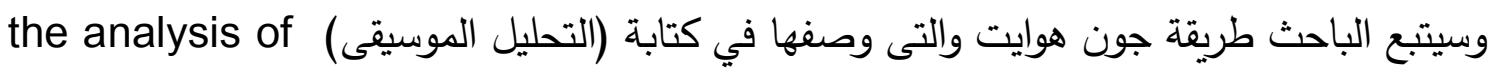
music

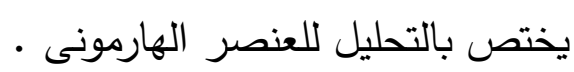
وفي البداية نذكر أن جون هوايت هو مؤلف موسيقى وأستاذ وناشر موسيقى أمريكي الجنسية ولد الدارئ الهوني

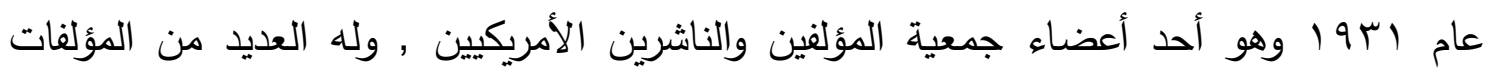

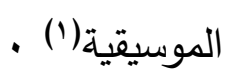

يرى جون هوايت أن أى عمل موسيقى من المكن أن يوصف وفقا للمستويات التالية :

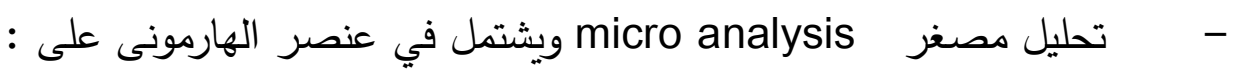

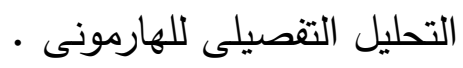
التوافق والتنافر . القفلات الهارمونية .

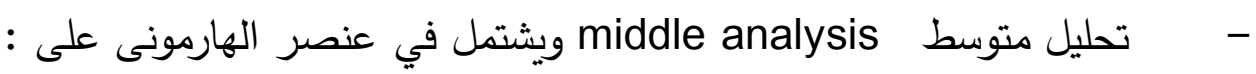
وجود الكنترابنطية أو البوليفونية .

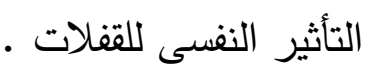

${ }^{1}$ White,john-the analysis of music-amazon.com-prentice hall publication-u.s.a-1976-p.13-18 .

مجلة علوم وفنون الموسيقى - كلية التربية الموسيقية - المجلد الخامس والأربعون - يوليو الr.بمر 
- - ملحليل شامل وواسع macro analysis ويشتمل في عنصر الهارمونى على :

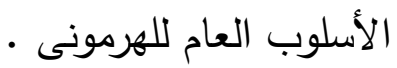

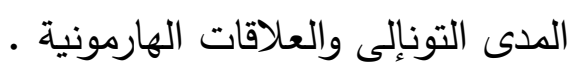

\section{ثانيا الاطار التطبيقى :}

سيقوم الباحث في الاطار التطبيقى بتحديد اطار التحليل في البداية وفق العناصر التالية :

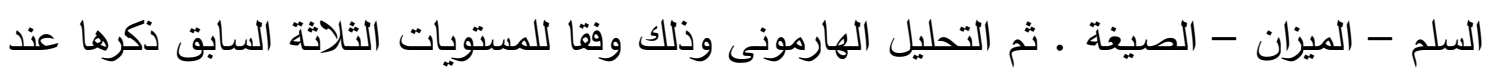
جون هوايت .

$$
\begin{aligned}
& \text { البريليود رقم (r) مصنف رقم(0) عند كابالفسكى . }
\end{aligned}
$$

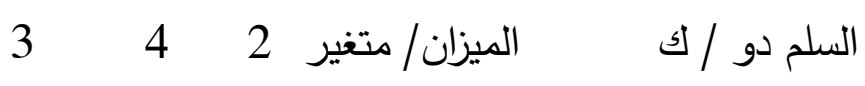

$$
\begin{aligned}
& 4-4-4
\end{aligned}
$$

one part form الصيغة / فكرة واحدة ثم يتم تكرارها مع التعديل + كوديتا

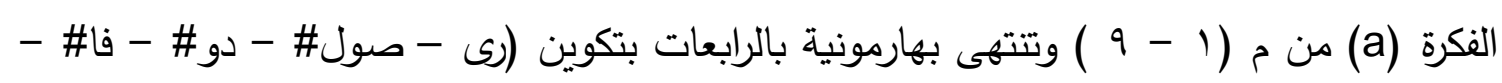

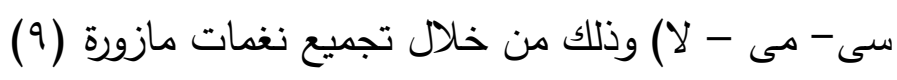

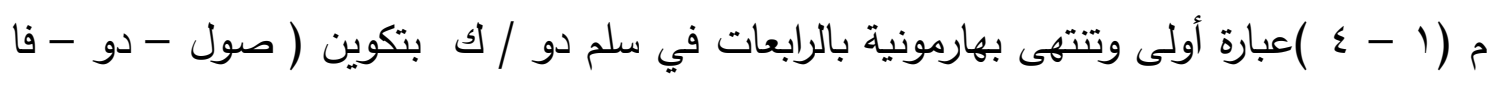

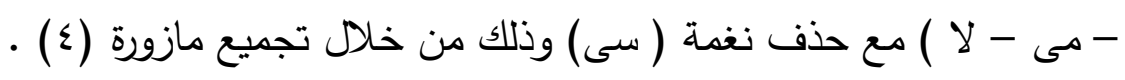

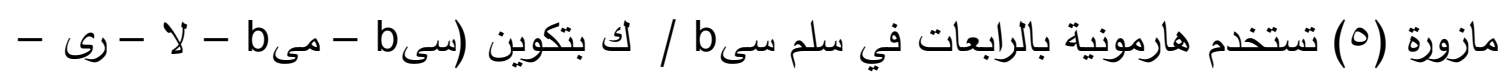
صول - دو - فا ) وهى خليط من الرابعات التامة والزائدة .

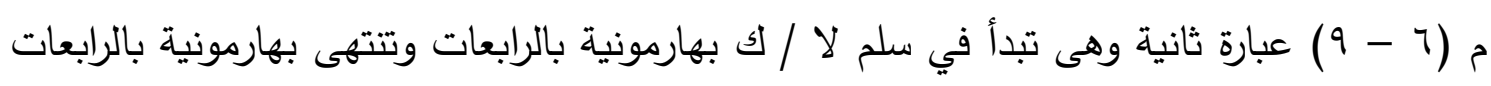

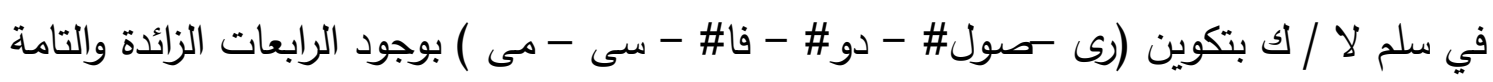

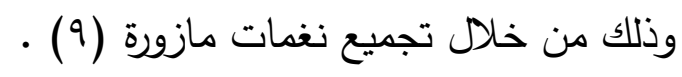

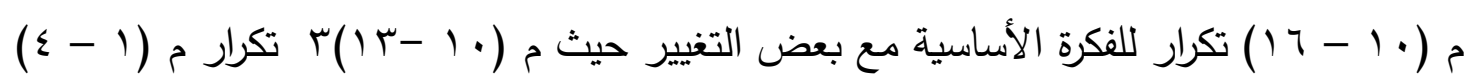

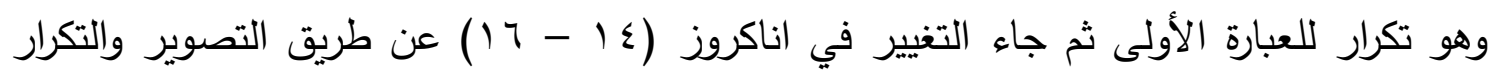

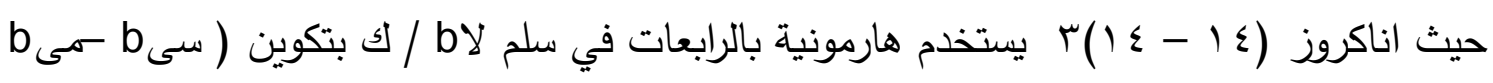

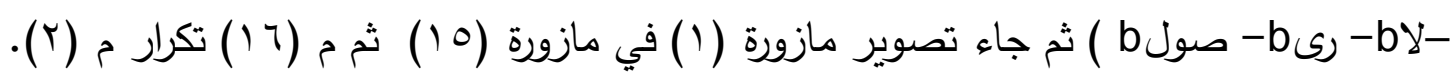

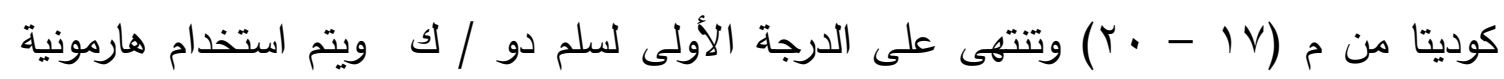

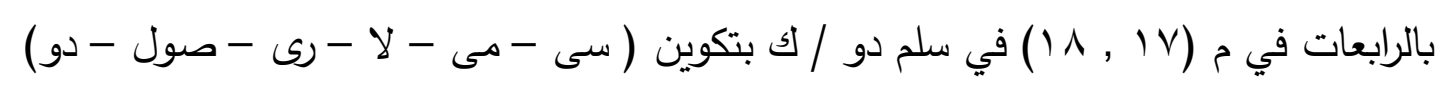

مجلة علوم وفنون الموسيقى - كلية التربية الموسيقية - المجلل الخامس والأربعون - يوليو I.r. 
وفي نهاية م (9 (1) تظهر هارمونية بالرابعات بتكوين (رى - صول -فال\# - سى - مى) مع حذف دف دئ

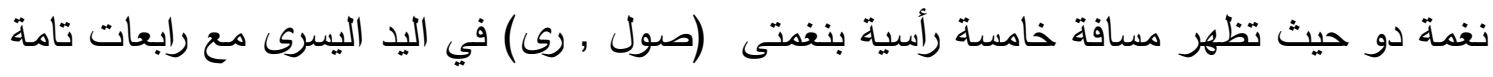

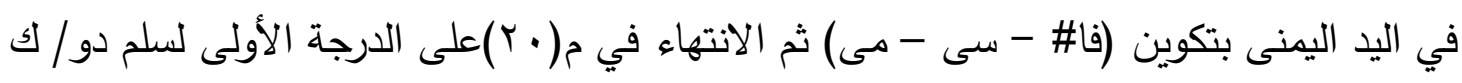

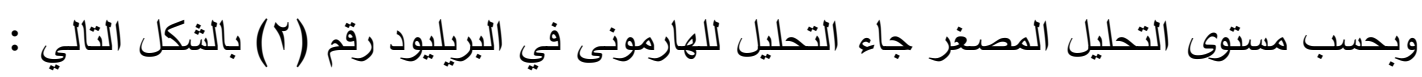

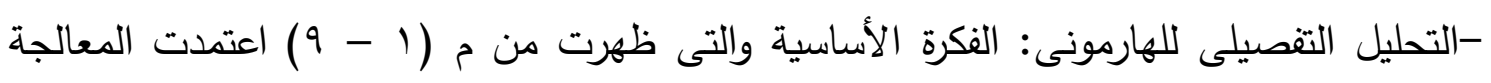

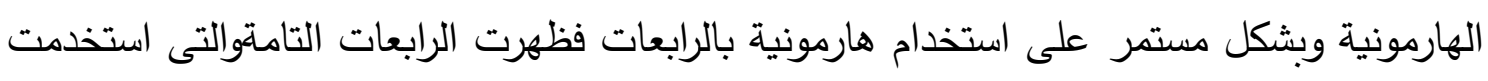

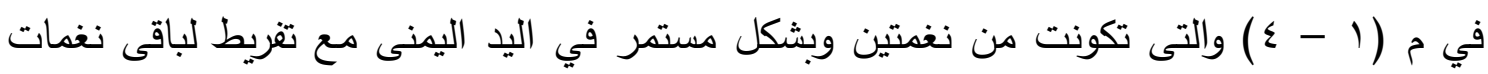

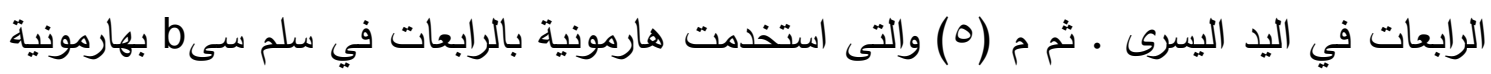

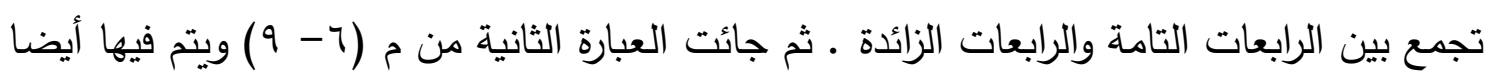
استخدام خليط من الرابعات التامة والزائدة .

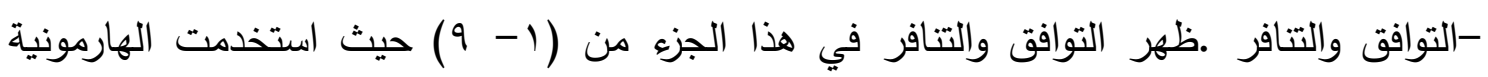

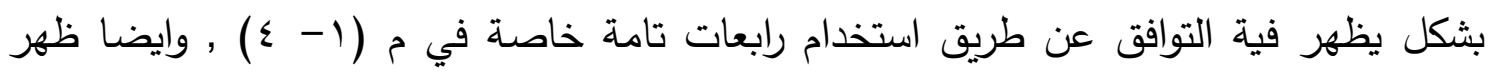

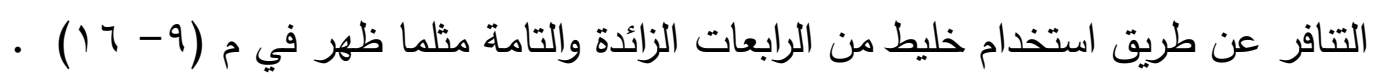

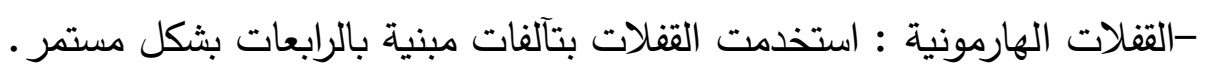
وبحسب مستوى التحليل المتوسط جاء التحليل الهارمونى بالثكل التالي :

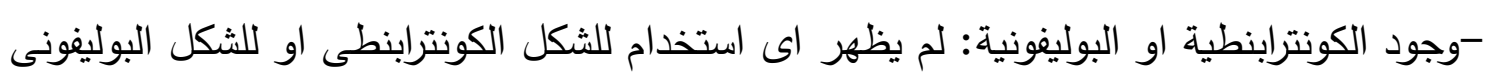

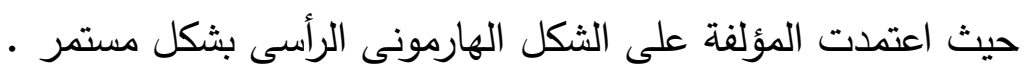

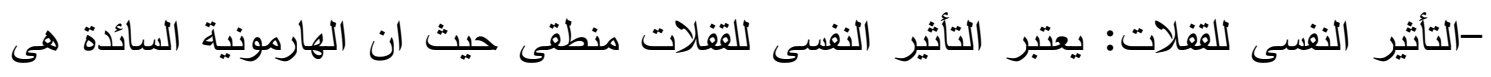
هارمونية بالرابعات والتى يتم فيها التعرض للرابعات التامة بشكل مسيطرمع وجود تجميعات للرابعات المختلطة .

وبحسب مستوى التحليل الثامل جاء التحليل الهارمونى بالثكل التالي :

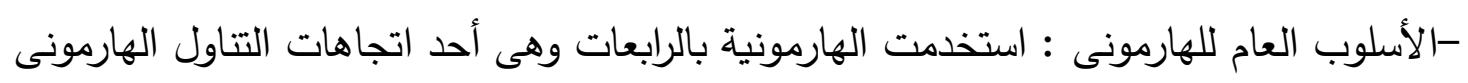

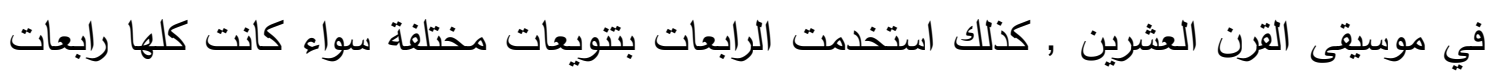
تامة أو كان هناك خليط من الرابعات وايضا جاءت الرابعات سواء من نغمتين أو أكثر .

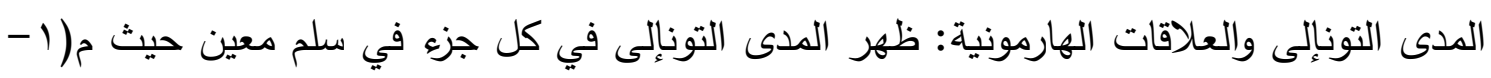

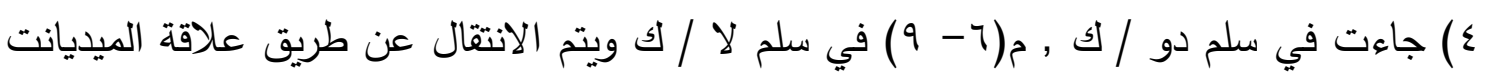

مجلة علوم وفنون الموسيقى - كلية التربية الموسيقية - المجلد الخامس والأربعون - يوليو اب.rمر 
الهابط , أما العلاقات الهارمونية فلم يتم فيها الاعتماد على الهارمونية التقليدية والتى يظهر فيها

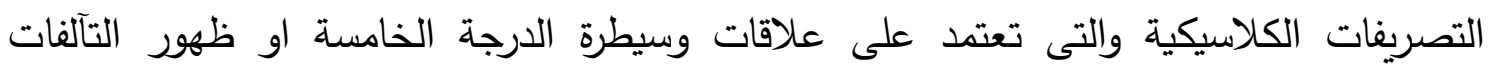
الثانوية أو الدياتونية ,ولكنها اعتمدت على تكوينات بالرابعات بثكل يخدم السلم المستخدم .

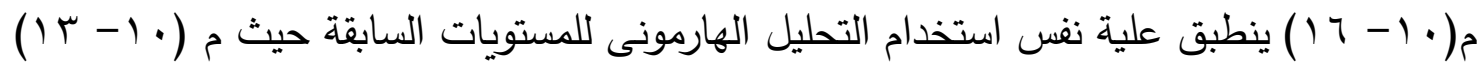

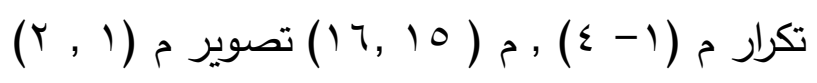

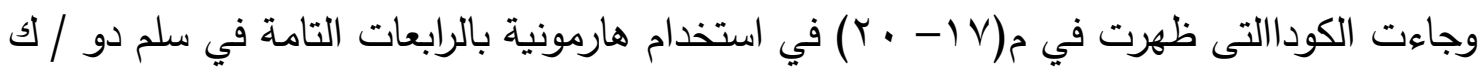

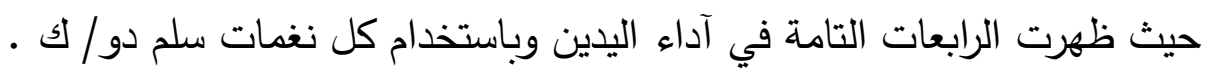

\section{نتائج البحث:}

- سيتضح من هذه الدراسة اهتمام بعض المؤلفين الموسيقيين في القرن العشرين لايجاد لغة هارمونية

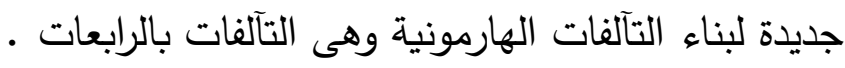
واظهرت الدراسة انة يمكن تكوين الهارمونيات بالرابعات التامة أو بخليط يجمع بين الرابعات التامة لتأكات والأخرى الزائدة .

-وأيضا من الممكن يظهر التآلف من خلال تجميع نغماتة بشكل رأسى من خلال تجميع الاستخدام

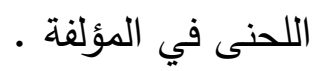
-كذلك من الممكن استخدام بعض طرق التحليل التى ظهرت في تحليل الأعمال الموسيقية في القرن العشرين , مثلما ظهر في الدراسة الحالية حيث استخدم الباحث طريقة جون هوايت في

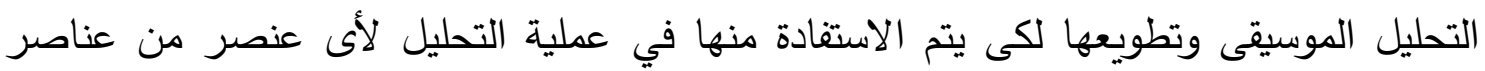

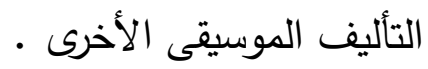

التوصيات:

-الاهتمام باجراء التحليل الهارمونى ولباقى عناصر التأليف الموسيقى خاصة لمؤلفي القرن العشرين حتى يتم التعرف على الاضافات المختلفة التى اضافها مؤلفي القرن العشرين في هذاء لاصني المجال. 
- تضمين مؤلفات كابالفسكى الموسيقية المختلفة ضمن مناهج التحليل الموسيقى وضمن مناهج التأليف في مرحلة الدراسات العليا وذلك للأهمية الكبرى التى يوليها العالم الموسيقى الخارجى لقيمة التئي هذا المؤلف الكبير -تنظيم الندوات الموسيقية والتى تتضمن الثرح والاستماع والتحليل لمؤلفي القرن العشرين والتعرف على كيفية تناولهم لأعمالهم الموسيقية وذلك حتى يتعرف الدارسون عليها وتساعدهم على الابداع . 
ا-سمحة الذولى -لقومية في موسيقى القرن العشرين - سلسلة كتب يصدرها المجاس الوطنى

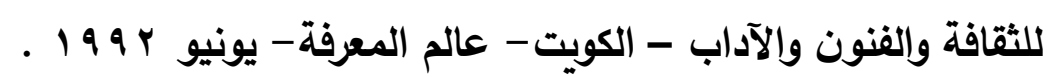

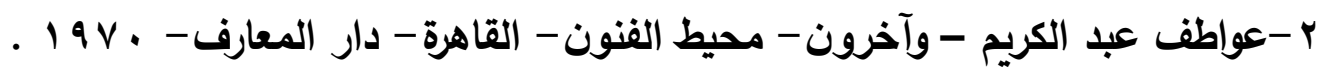

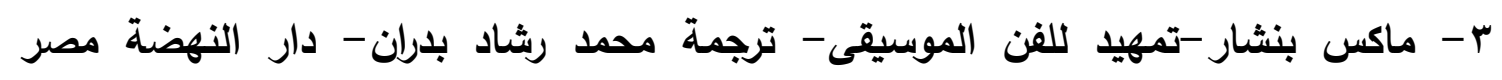

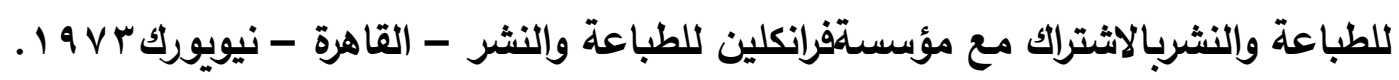
4-Apel,willi-harvard dictionary of music-second ed-london-heinemann educational-book,s-ltd.1983.

5-Dallin,leon-techniques of twentieth century composition-third edwm.c.brown company publishers -u.s.a. 1980.

6-Ewen,david-twentieth century music-prentice hall-inc.,new tork-1954.

7- Kabalevsky,maria-memories of my father-nepta-new England piano teacher,s-assoc-inc., 1994.

8- Persichitte,Vincent-twentieth century harmony-creative aspectice and practice-u.s.a-vail-ballou-press,inc. 1978.

9- Sadie,stanly-the new grove,sdictionary of music and musicians-vol 13 maacmillanpublishers-new York- 2001.

10- Sir Westrup,jackand Harrison,f.li.-rvised by Wilson,Conrad- Collins pocket dictionary of music-wm.collins sons \&co.ltd.london-1984.

11- White,john david-the analysis of music -amazon-com:books -publisher prentice hall publication - u.s.a-1967.

مجلة علوم وفنون الموسيقى - كلية التربية الموسيقية - المجلد الخامس والأربعون - يوليو ابr.rم 


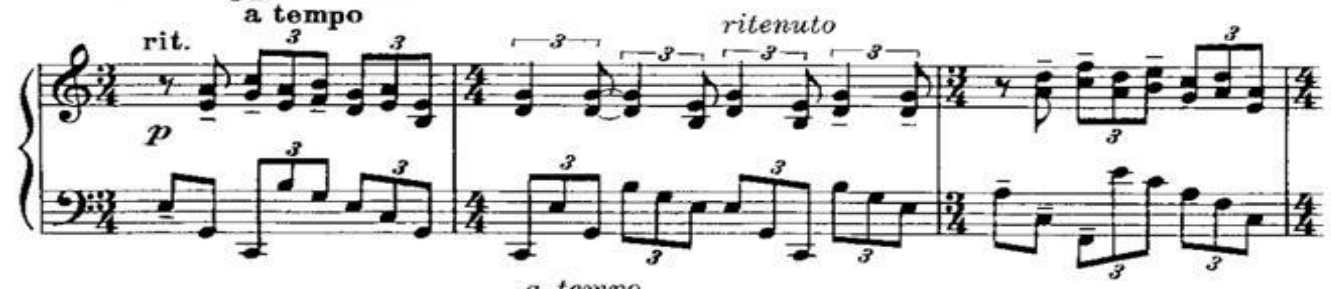

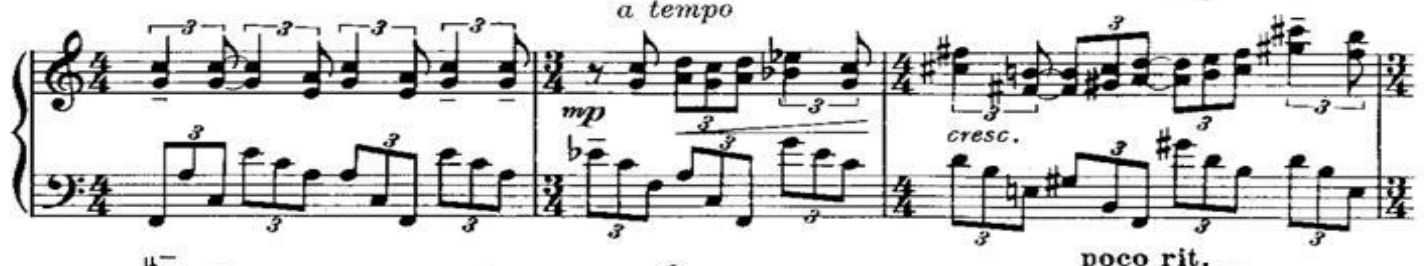
$\left\{\left(\frac{6}{2}\right.\right.$

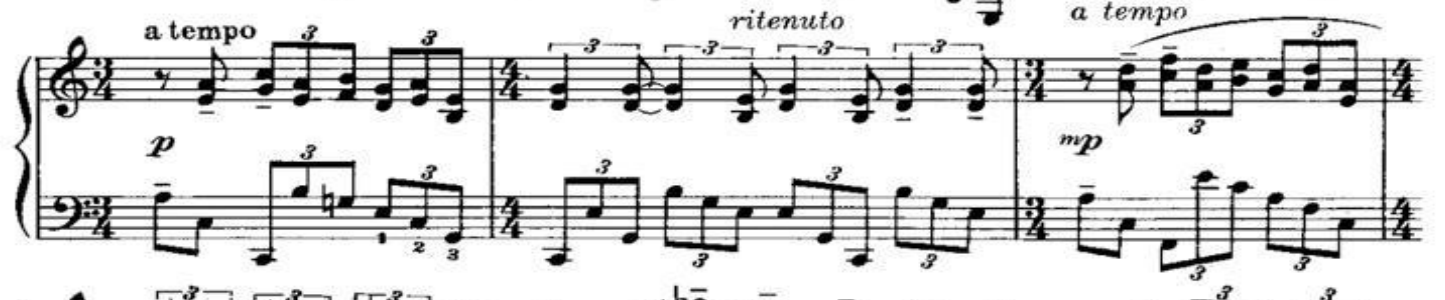

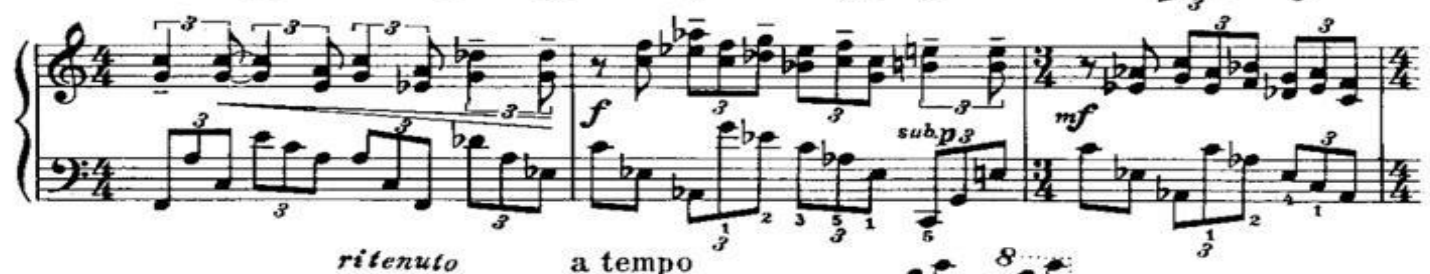

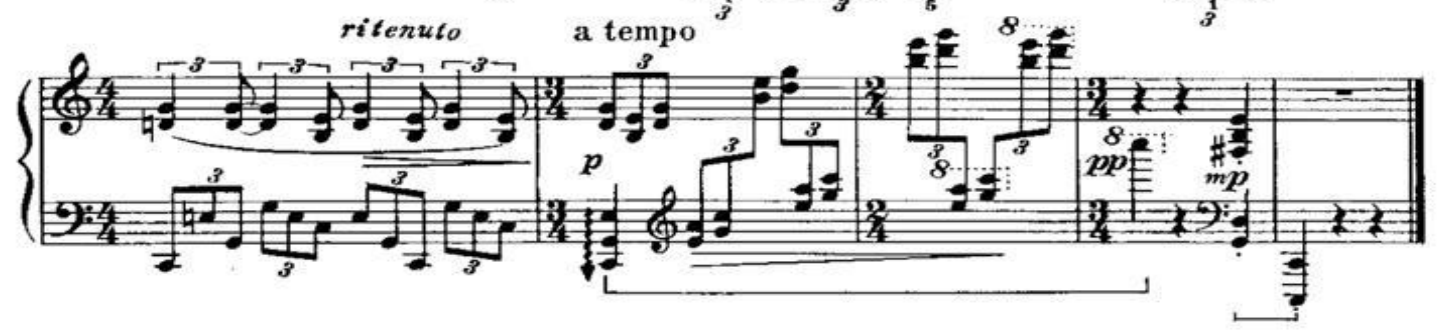

مجلة علوم وفنون الموسيقى - كلية التربية الموسيقية - المجلد الخامس والأربعون - يوليو ابrمه 


\section{ملخص البحث باللغة العربية}

استخدام طريقة جون هوايت john white في التحليل الهارمونى في بريليود رقم(؟) مصنف بالفيه

$$
\text { رقم(0) عند كابالفسكى }
$$

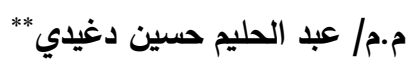

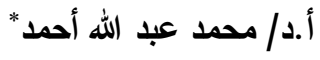

شها القرن العشرين تجديدات متعددة في الموسيقا بكل عناصره خاصة عناصر اللحن والهارمونى

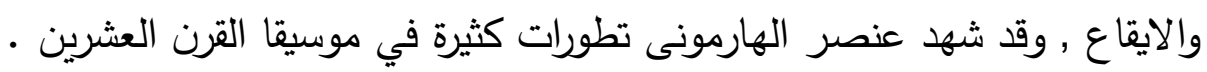

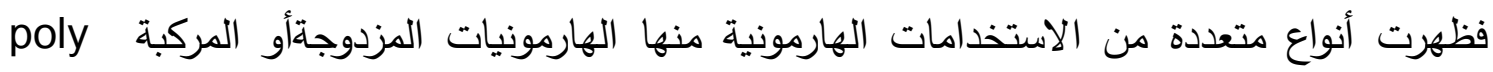

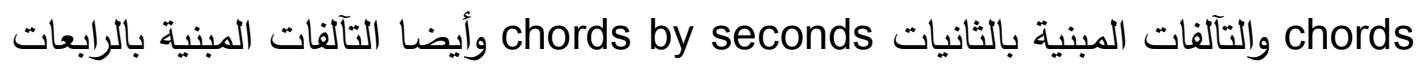
chords by fourths عناصرها , واستخدم معظم مؤلفي القرن العشرين هذه التجديدات في مؤلفاتهم الموسيقية , وتناولوها برؤية تخدم التجديدات المختلفة ومنهم المؤلف الموسيقى الروسى كابالفسكى والذى استخدم بعض

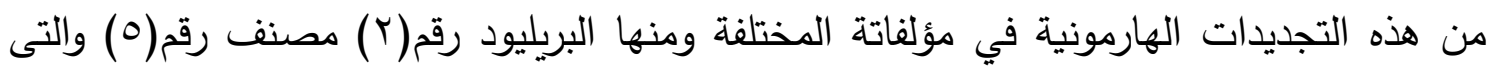
تناولها الباحث بالتحليل الهارمونى وفق طريقة جون هوايت والتى شرحها في كتابة التحليل

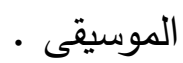
ويشتمل هذا البحث على جزئين :

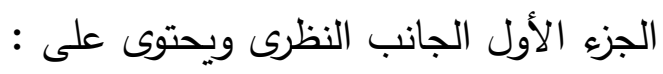

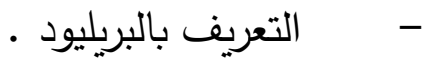

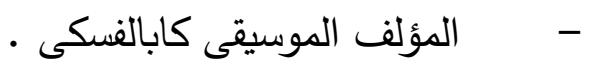

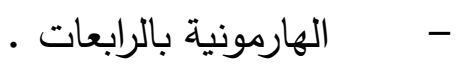

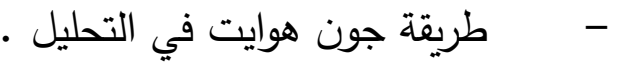
الجزء الثانى : الجانب التطبيقى ويحتوى على: الدراسة التحليلية لعينة البحث - نتائج البحث - التوصيات - المراجع - ملخص البحث باللغة العربية - ملخص البحث باللغة الأجنبية .

* محمد عبد الله: أستاذ دكتور بقسم النظريات و التأليف ـ شعبة تأليف، كلية التربية الموسيقية، جامعة حلو ان.

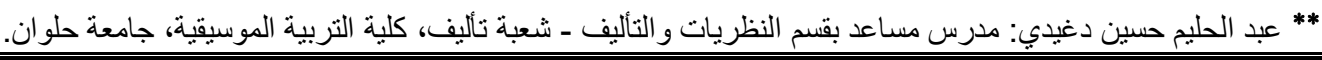

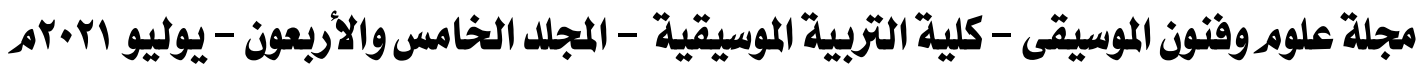


summary

\section{John white method in analysis of harmonic in kabalevsky's prelude no. 2 op. 5}

with advent of the twentieth century music a new styles and techniques appears especially the element of melody, harmony, and rhythm .

harmony witness more development in twentieth century music.

Multy kinds on uses for harmony appears sush as poly chords, chords by seconds and chords by fourths . so twentieth century the era of renovations in all music elemens. Most composers of twentieth century uses these renovations in all musical composition .and they uses it with a vision to serving different renovations .

For example Russian composer kabalevsky who use some of these harmonic renovations in some of his different compositional gike preludeno 2 op 5 which it will be coverd by the researcher with analysis harmonic according to jhon white,s way which explain it hn his book the analysis of music .

This searchcosists of two parts ;

The first A theoretical side which is contains ;

Prelude - Dmitry kabalevsky - chords by fourths - john white way in analysis of music

The second an analytical study which contains the analytical of prelude no 2 op 5 for kabalevsky - research results - recommendations -references- research summary in Arabic - research summory in English .

مجلة علوم وفنون الموسيقى - كلية التربية الموسيقية - المجلد الخامس والأربعون - يوليو ابr.rم 